\title{
Intolerância religiosa dos evangélicos na educação básica: \\ breve análise de alguns casos
}

FIOROTTI, Silas ${ }^{1}$

\section{RESUMO}

O artigo apresenta uma breve análise de dezoito casos de intolerância religiosa ocorridos, entre 2004 e 2018, no âmbito da educação básica; e também uma reflexão sobre duas atividades. Estes casos foram classificados em cinco tipos de intolerância religiosa na educação básica. Seguindo a perspectiva antropológica que identifica a presença do religioso nas proibições, identificouse diversas proibições em relação às religiões e aos símbolos afro-brasileiros. Apontou-se que o religioso presente nas escolas está associado a um Deus belicoso do pentecostalismo que propaga a guerra espiritual. Os casos analisados indicam que quem mais sofre com a intolerância religiosa nas escolas são pessoas adeptas das religiões afro-brasileiras e negras, e quem mais comete os atos de intolerância religiosa são pessoas evangélicas. E, por fim, como medida de combate à intolerância religiosa, há um apelo para que estudantes, professores e demais profissionais da educação estejam efetivamente em contato e em diálogo com os religiosos afro-brasileiros.

Intolerância Religiosa. Educação Básica. Religião. Evangélicos e

Afro-Brasileiros.

\section{Religious intolerance of evangelicals in basic education: brief analysis of some cases}

\section{ABSTRACT}

The article presents a brief analysis of eighteen cases of religious intolerance that occurred between 2004 and 2018 in the area of basic education; and also a reflection on two activities. These cases were classified into five types of religious intolerance in basic education. Following the anthropological perspective that identifies the presence of the religious in the prohibitions, several prohibitions were identified regarding the religions and the Afro-Brazilian symbols. It was pointed out that the religious present in schools is associated with a bellicose God

\footnotetext{
${ }^{1}$ Doutor em Antropologia Social, professor colaborador no Centro de Pesquisa e PósGraduação (CPPG) do Complexo Educacional FMU, pesquisador colaborador no CERNe-USP e no CERU-USP. E-mail: silas.fiorotti@gmail.com. Lattes:

http://lattes.cnpq.br/6609227955714814. ORCID: https://orcid.org/0000-0003-4691-0010.

\begin{tabular}{l|l} 
REVISTA & Interritórios | Revista de Educação \\
interritórios & $\begin{array}{l}\text { Universidade Federal de Pernambuco, } \\
\text { Caruaru, BRASIL | V.5 N.9 [2019] }\end{array}$
\end{tabular}
}


of Pentecostalism who propagates spiritual warfare. According to the cases analyzed, it was found that those who suffer most from religious intolerance in schools are people who are adherents of Afro-Brazilian religions and black people, and those who commit acts of religious intolerance are evangelical believers. And finally, as a measure to combat religious intolerance, there is an appeal for students, teachers and other professionals in education to be effectively in contact and in dialogue with Afro-Brazilian religious.

Religious Intolerance. Basic Education. Religion. Evangelicals and

Afro-Brazilian.

Intolleranza religiosa degli evangelici nell'istruzione di base: una breve analisi di ocorrenze

\section{RIASSUNTO}

l'articolo presenta una breve analisi di diciotto casi di intolleranza religiosa verificati tra il 2004 e il 2018, nell'ambito dell'istruzione di base; e anche una riflessione su due attività. Questi casi sono stati classificati in cinque tipi di intolleranza religiosa nell'istruzione di base. Seguendo la prospettiva antropologica che identifica la presenza dei religiosi nei divieti, abbiamo identificato diversi divieti in relazione alle religioni e ai simboli afro-brasiliani. È stato sottolineato che il presente religioso nelle scuole è associato a un dio bellicoso del pentecostalismo che propaga la guerra spirituale. I casi analizzati indicano che coloro che soffrono maggiormente dell'intolleranza religiosa nelle scuole sono persone che aderiscono alle religioni afro-brasiliane e nere, e coloro che commettono più atti di intolleranza religiosa sono persone evangeliche. $E$ infine, come misura per combattere l'intolleranza religiosa, c'è un appello per studenti, insegnanti e altri professionisti dell'educazione a essere effettivamente in contatto e nel dialogo con i religiosi afro-brasiliani.

Intolleranza religiosa. Istruzione di base. Religione. Evangelici e

Afro-brasiliani.

\section{Intolerancia religiosa de los evangélicos en la educación básica: breve análisis de algunos casos}

\section{RESUMEN}

El artículo presenta un breve análisis de dieciocho casos de intolerancia religiosa ocurridos entre 2004 y 2018 en el área de educación básica; y también una reflexión sobre dos actividades. Estos casos se clasificaron en cinco tipos de intolerancia religiosa en la educación básica. Siguiendo la perspectiva

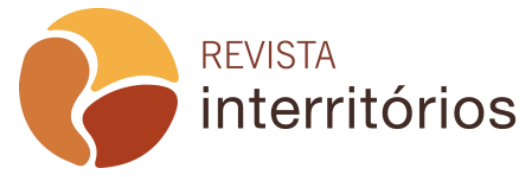

Interritórios | Revista de Educação Universidade Federal de Pernambuco, Caruaru,BRASIL | V.5 N.9 [2019] 
antropológica que identifica la presencia de los religiosos en las prohibiciones, se identificaron varias prohibiciones con respecto a las religiones y los símbolos afrobrasileños. Se señaló que el presente religioso en las escuelas está asociado con un Dios belicoso del pentecostalismo que propaga la guerra espiritual. Según los casos analizados, se descubrió que quienes sufren más de intolerancia religiosa en las escuelas son personas que son adherentes a las religiones afrobrasileñas y personas negras, y quienes cometen actos de intolerancia religiosa son creyentes evangélicos. Y, por último, como medida para combatir la intolerancia religiosa, existe un llamamiento para que los estudiantes, los docentes y otros profesionales de la educación mantengan un contacto y un diálogo eficaces con los religiosos afrobrasileños.

Intolerancia religiosa. Educacion basica. Religión. Evangélicos y

Afrobrasileño.

\section{INTRODUÇÃO}

O imaginário que toma o Brasil como o país da liberdade religiosa consolidada, da tolerância religiosa e das misturas de crenças vem sendo desafiado pelo crescimento dos casos caracterizados como intolerância religiosa. $\mathrm{O}$ crescimento destes casos de intolerância religiosa, constatado nos últimos anos, tem sido relacionado diretamente com o racismo e com 0 crescimento do pentecostalismo. Os ensinamentos e as práticas pentecostais, assim como os ensinamentos e as práticas evangélicas de uma forma geral, não têm se caracterizado pela preconização do diálogo e da convivência pacífica entre crentes evangélicos e adeptos das religiões afro-brasileiras (ou religiões brasileiras de matrizes africanas). Pelo contrário, apesar de algumas iniciativas tímidas de indivíduos e grupos evangélicos no sentido do diálogo e da convivência pacífica, as religiões afro-brasileiras e suas divindades continuam sendo amplamente demonizadas nas igrejas pentecostais.

A partir da década de 1970, a batalha ou guerra espiritual passou a ter um lugar central no sistema teológico e doutrinário de grande parte do pentecostalismo brasileiro. A demonização das religiões afro-brasileiras, que já estava presente anteriormente no pentecostalismo, passou a ser difundida e enfatizada como parte da batalha ou guerra espiritual, e levou a um acirramento das práticas pentecostais com convocações, por parte de igrejas e líderes, para os fiéis cometerem atos que podem ser caracterizados como intolerância religiosa. Nesta batalha ou guerra espiritual, os principais alvos dos ataques pentecostais têm sido as religiões afro-brasileiras, suas divindades, seus adeptos e os demais símbolos da herança africana no Brasil (cf. ORO, 1997). ${ }^{2}$

\footnotetext{
2 Diversos pesquisadores denominam estes ataques, encabeçados por indivíduos e grupos evangélicos e direcionados contra as religiões afro-brasileiras, de "ataques neopentecostais"

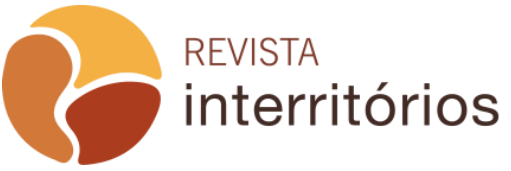

Interritórios | Revista de Educação Universidade Federal de Pernambuco, Caruaru,BRASIL | V.5 N.9 [2019]
} 
Uma literatura da batalha ou guerra espiritual foi desenvolvida e muito difundida entre os pentecostais brasileiros. Esta literatura coloca as religiões afro-brasileiras como alvo principal a ser combatido. Entre os exemplos mais conhecidos está o livro Orixás, Caboclos e Guias: Deuses ou Demônios? do bispo Edir Macedo (1997), líder da Igreja Universal do Reino de Deus. O título deste livro já indica que Macedo volta-se contra o candomblé, a umbanda e o espiritismo. Esta literatura desenvolvida no Brasil foi influenciada por diversos autores evangélicos norte-americanos. Cabe mencionar o livro Oração de Guerra do pastor norte-americano C. Peter Wagner (1992) que, por sua vez, influenciou e ainda influencia muitos líderes pentecostais brasileiros. Neste livro, Wagner trata especificamente sobre a "guerra espiritual em nível estratégico". No capítulo intitulado As Regras para Conquista de Cidades, ele adota a definição de evangelização como uma "guerra espiritual contra as forças ativas das trevas", e apresenta seis regras para, através da guerra espiritual, conquistar uma cidade:

(1) "selecione uma área geográfica manipulável com fronteiras espirituais discerníveis"; (2) "obtenha a unidade dos pastores e outros líderes cristãos da área, para que comecem a orar juntos em uma base regular"; (3) "projete uma imagem clara de que o esforço não é apenas dos pentecostais e carismáticos, mas do inteiro Corpo de Cristo"; (4) "garanta a preparação espiritual dos líderes e outros crentes participantes mediante 0 arrependimento, a humildade e a santidade"; (5) "pesquise a formação histórica da cidade, a fim de revelar as forças espirituais que têm moldado a cidade"; e (6) "trabalhe com intercessores dotados e chamados para a guerra em nível estratégico, buscando a revelação de Deus sobre: o dom ou dons remidores da cidade, as fortalezas de Satanás na cidade, os espíritos territoriais atribuídos à cidade, o pecado coletivo passado e presente que precisa ser tratado, e o plano e o cronograma de ataque de Deus" (WAGNER, 1992, p. 156-174).

Este tipo de evangelização proposta por C. Peter Wagner caracteriza-se como um estímulo a muitos indivíduos e grupos evangélicos cometerem atos que podem ser caracterizados como intolerância religiosa.

O antropólogo Vagner Gonçalves da Silva (2007a; 2007b; 2013) classificou diversos atos ou ataques pentecostais direcionados contra as religiões afro-brasileiras, ocorridos principalmente no início da década de 2000 , segundo alguns critérios específicos:

(cf. Bortoleto, 2014; Oro, 1997; Silva, 2007a; 2007b; 2013). Sobre o chamado neopentecostalismo, ver: Freston (1994), Mariano (1999), e Mendonça (2008), entre outros.

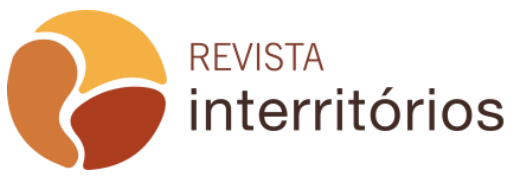

Interritórios | Revista de Educação Universidade Federal de Pernambuco, Caruaru,BRASIL | V.5 N.9 [2019] 
(1) ataques feitos no âmbito dos cultos das igrejas neopentecostais e em seus meios de divulgação e proselitismo; (2) agressões físicas in loco contra terreiros e seus membros; (3) ataques às cerimônias religiosas afro-brasileiras realizadas em locais públicos ou aos símbolos destas religiões existentes em tais espaços; (4) ataques a outros símbolos da herança africana no Brasil que tenham alguma relação com as religiões afrobrasileiras; (5) ataques decorrentes das alianças entre igrejas e políticos (geralmente evangélicos), associações protetoras de animais e ambientalistas; e (6) as reações públicas (políticas e judiciais) dos adeptos das religiões afro-brasileiras (SILVA, 2013, p. 148).

Ou seja, estes ataques não são praticados apenas no âmbito dos cultos, na literatura de guerra ou batalha espiritual e outros meios de divulgação das igrejas. Foram noticiados na imprensa e citados por pesquisadores alguns casos de agressões físicas contra adeptos das religiões afro-brasileiras, invasões de terreiros, ataques às cerimônias religiosas afro-brasileiras em locais públicos e aos símbolos dessas religiões, e ataques aos símbolos da herança africana no Brasil.

O caso de Mãe Gilda (Gildásia dos Santos e Santos), do Axé Abassá de Ogum, em Itapuã, é paradigmático. Em 2000, ela faleceu de um infarto fulminante em decorrência dos ataques sofridos por grupos pentecostais. Além de ter sua imagem utilizada indevidamente por uma igreja, teve seu terreiro invadido por um grupo de evangélicos dispostos a "exorcizá-la". Este caso levou a Câmara Municipal de Salvador, em 2004, a transformar a data de seu falecimento, o dia 21 de janeiro, em Dia Municipal de Combate à Intolerância Religiosa. Posteriormente, em 2007, o mesmo dia tornou-se o Dia Nacional de Combate à Intolerância Religiosa. Este caso mostra que os adeptos das religiões afro-brasileiras foram levados a buscar alianças e reagir publicamente contra os ataques pentecostais e contra a intolerância religiosa de uma forma geral. Nos últimos anos, o movimento contra a intolerância tem ganhado força e, consequentemente, houve um aumento considerável no número de denúncias de intolerância religiosa (cf. ALVES; FIOROTTI, 2014).

Alguns casos mais recentes de intolerância religiosa estão relacionados com as alianças entre pastores e "traficantes evangélicos". Trata-se de algo que tem ocasionado diversos ataques contra terreiros e adeptos das religiões afrobrasileiras, até mesmo a expulsão destes de bairros e comunidades que estão sob o domínio dos criminosos, principalmente nas cidades do Rio de Janeiro e de Salvador (cf. SILVA, 2013, p. 153).

Outros casos mais recentes de intolerância religiosa têm ocorrido no âmbito da educação básica. 


\section{Alguns casos de intolerância religiosa na educação básica}

Diversos casos de intolerância religiosa na educação básica estão relacionados com a resistência à implementação da lei 10.639 de 2003 que tornou obrigatório o ensino da história e da cultura africana e afro-brasileira nas escolas. Não é somente uma resistência a esta lei, mas também resistência às obras clássicas da literatura brasileira que abordam as religiosidades populares e afro-brasileiras. Quando a lei é colocada em prática, as religiões afrobrasileiras raramente são mencionadas por conta da oposição de alguns grupos religiosos, especialmente dos evangélicos (cf. ARAÚJO, 2015; BAKKE, 2011).

Em 2016, o relatório da Comissão de Combate à Intolerância Religiosa estimou que, entre 2011 e 2015 , mais de $70 \%$ dos atos de intolerância religiosa foram cometidos contra praticantes das religiões afro-brasileiras. $O$ relatório também apontou que as pessoas que mais cometem estes atos são: primeiramente desconhecidos, depois vizinhos e, em terceiro lugar professores (cf. FERREIRA; GRADELLE, 2017). O Ministério dos Direitos Humanos (MDH) disponibilizou, em agosto de 2018, um balanço das denúncias de casos de intolerância religiosa do Disque 100, telefone da Ouvidoria Nacional de Direitos Humanos; denúncias recebidas entre 2011 e o primeiro semestre de 2018. Este balanço apontou que diversas denúncias são relativas a casos ocorridos nas escolas e a casos cometidos por professores e diretores de escolas (cf. MDH, 2018). ${ }^{3}$ Estes dados indicam o crescimento da intolerância religiosa na educação básica. Não há somente uma resistência à abordagem das religiões afrobrasileiras e à implementação da lei 10.639 por parte dos professores e demais profissionais da educação, há também atos de intolerância religiosa praticados por eles. No entanto, a própria falta de levantamentos e pesquisas mais exaustivos sobre a intolerância religiosa de um modo geral, e especificamente sobre os casos ocorridos no âmbito da educação básica, dificulta a compreensão das diversas dimensões desta intolerância religiosa e a proposição de medidas para combatê-la.

Cito abaixo dezoito casos de intolerância religiosa ocorridos, entre 2004 e 2018, no âmbito da educação básica. Estes casos foram noticiados na imprensa e alguns foram citados em pesquisas acadêmicas.

\footnotetext{
${ }^{3}$ Este balanço das denúncias do Disque 100 indicou o número de denúncias de casos de intolerância religiosa ocorridos nas escolas (local da violação): 11 (9,82\%) em 2012, 25 $(10,46 \%)$ em 2013, 8 (5,19\%) em 2014, 11 (4,31\%) em 2015, 19 (4,60\%) em 2016, 24 (6,59\%) em 2017, 9 (5,88\%) no 1. sem. 2018; e o número de denúncias com atos de intolerância religiosa cometidos por professores e diretores de escolas (suspeitos): $12(6,15 \%)$ em 2012, 28 (12,03\%) em 2013, 15 (5,86\%) em 2014, 8 (2,05\%) em 2015, 26 (3,47\%) em 2016, 19 (2,97\%) em 2017, 6 (2,36\%) no 1. sem. 2018. No entanto, há muitas denúncias (entre $20 \%$ e $47 \%$ ) sem dados específicos e colocadas nas categorias Outros (local da violação) e Não informado (suspeito) (cf. MDH, 2018).
}

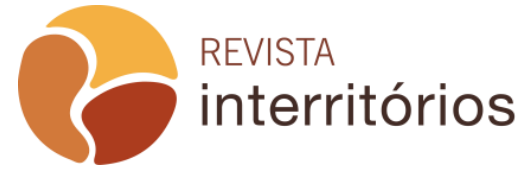

Interritórios | Revista de Educação Universidade Federal de Pernambuco, Caruaru,BRASIL | V.5 N.9 [2019] 
(1) Em 2004, houve protestos, por parte de evangélicos, contra os livros didáticos da Coleção História Paratodos da autoria de Conceição Oliveira (2004), especificamente o capítulo Nossas Raízes Africanas do volume da segunda série do ensino fundamental. Este capítulo trata da formação das religiões afrobrasileiras e propõe aos estudantes uma pesquisa sobre a história dos orixás. Uma coordenadora pedagógica evangélica, da cidade de Belford Roxo, no Rio de Janeiro, protestou junto à editora contra o conteúdo do livro (cf. SILVA, 2007a, p. 220; 2007b, pp. 16-17; 2013, pp. 159-160).

(2) Em 2004, um vereador e pastor evangélico da cidade de Pato Branco, no Paraná, também protestou contra o conteúdo do livro da Coleção História Paratodos, denominando a obra de "livro do demônio", e pediu a sua cassação. Apesar destes protestos, a coleção recebeu parecer favorável do Ministério da Educação, foi recomendada pelo Plano Nacional do Livro Didático e, em 2005, recebeu o Prêmio Jabuti na categoria didático e paradidático (cf. SILVA, 2007a, p. 220; 2007b, pp. 16-17; 2013, pp. 159-160).

(3) Em 2005, a diretora de uma escola, no bairro de Stella Maris, na cidade de Salvador, Bahia, mandou apagar a figura do orixá Ogum pintada em painel artístico dentro do edifício escolar. A diretora agiu desta forma por pressão de pais evangélicos da comunidade escolar (cf. SILVA, 2007a, p. 219; 2007b, pp. 14-15; 2013, p. 158).

(4) Em 2008, o estudante Felipe Gonçalves Pereira, adepto do candomblé, foi expulso da sala de aula por uma professora evangélica por usar um fio de conta no pescoço, a professora chamou o estudante de "filho do capeta". Este fato ocorreu numa escola estadual (Faetec), na cidade do Rio de Janeiro. Após sete meses, a escola emitiu um comunicado oficial pedindo publicamente desculpas ao estudante, a seus familiares e aos adeptos do candomblé (cf. MONTEAGUDO, 2009a; SILVA, 2013, p. 156).

(5) Em 2009, a professora Maria Cristina Marques de uma escola municipal na cidade de Macaé, no Rio de Janeiro, acusou a diretora de perseguição. A professora relatou que foi afastada de suas atividades pela diretora evangélica, com o apoio de pais evangélicos da comunidade escolar, por conta da utilização do livro Lendas de Exu de Adilson Martins (2008). Cabe lembrar que este livro também foi recomendado pelo Plano Nacional do Livro Didático (cf. ARAÚJO 2015, p. 191; MONTEAGUDO, 2009b; SILVA, 2013, p. 160).

(6) Em 2010, foi amplamente divulgada uma pesquisa sobre o conteúdo de 25 livros didáticos de ensino religioso (cf. Diniz, Lionço e Carrião, 2010). A pesquisa apontou que a maior parte do conteúdo destes livros (mais de 65\%) é dedicada ao 
cristianismo, inclusive diversas editoras que publicam os livros são editoras religiosas (católicas e evangélicas). Isto em si não é um problema, já que diversos estados e municípios adotaram o ensino religioso de modelo confessional. No entanto, não deixa de ser problemática a forma como as religiões minoritárias são retratadas nos livros, principalmente as religiões afro-brasileiras e as religiosidades indígenas. Isto é algo ainda mais problemático se pensarmos que estes livros são adotados também nas aulas de ensino religioso de modelos interconfessional e não confessional. O que se pode concluir é que a falta de um paradigma nacional para o ensino religioso e a ausência de diretrizes curriculares definidas para a disciplina têm gerado livros didáticos que invariavelmente apresentam as religiões minoritárias de forma preconceituosa, subrepresentadas ou mesmo sem o reconhecimento como religiões (cf. BORGES, 2010; FIOROTTI, 2017; GARRIDO, 2012; MARIZ, 2010; VIERA e BIAZETTO, 2013).

(7) Em 2012, um grupo de estudantes evangélicos da Escola Estadual Senador João Bosco Ramos de Lima, na cidade de Manaus, Amazonas, se recusou a apresentar um trabalho sobre cultura africana e cultura indígena a partir da literatura brasileira. Estes estudantes evangélicos se negaram a ler livros clássicos da literatura brasileira alegando que esta leitura feria "princípios bíblicos". Contrariando as recomendações dos professores e desrespeitando o plano de ensino, os estudantes evangélicos apresentaram o trabalho intitulado Missões na África, abordando as missões evangélicas no continente africano (cf. ARAÚJO, 2015, pp. 188-189; MELO, 2012).

(8) Em 2014, um estudante candomblecista de 12 anos, da Escola Municipal Francisco Campos, na cidade do Rio de Janeiro, foi constrangido pela diretora e impedido de entrar na escola vestindo bermuda branca, boné e fios de conta. Estes itens faziam parte do preceito de iniciação do estudante no candomblé e ele deveria utilizá-los durante três meses. A mãe do estudante tentou negociar com uma professora e com a diretora, mas não foi possível, a diretora alegou que a bermuda branca e o boné não faziam parte do uniforme escolar. Este episódio obrigou a mãe a recorrer à Coordenadoria Regional de Educação para transferir o estudante para outra escola da região (cf. ARAÚJO, 2015, pp. 193-194; MACHADO, 2014).

(9) Em 2015, a estudante candomblecista Agnes do Colégio Estadual Alfredo Parodi, na cidade de Curitiba, Paraná, foi agredida em sala de aula por outra estudante após ter publicado em rede social, no dia anterior, foto tirada em terreiro de candomblé. A agressora não queria ficar perto de Agnes porque "ela era da macumba" (cf. BOECHAT, 2015).

(10) Em 2016, um grupo de estudantes de uma escola particular (Centro de Educação Trindade) da cidade de Ananindeua, no Pará, foi impedido de apresentar um trabalho sobre a Pombagira na feira cultural da escola. A diretora Ana Trindade disse aos 
estudantes: "aqui dentro da minha escola vai funcionar, vai se realizar e vai se apresentar o que eu achar que é de Deus. Nada de Pombagira aqui dentro" (cf. SÓTER; YURI, 2016).

(11) Em 2016, o estudante candomblecista Kayque Ferraz da cidade de Duque de Caxias, Rio de Janeiro, relatou que era obrigado a rezar o Pai Nosso em sala de aula (cf. FERREIRA; GRANDELLE, 2017).

(12) Em 2016, Gilberto Garcia, membro do Conselho Nacional de Educação (CNE), afirmou que muitos pais de estudantes entraram em contato com o CNE para reclamar do ensino de história africana: "diziam que era macumba" (cf. FERREIRA; GRANDELLE, 2017).

(13) Em 2017, a estudante Kethelyn Coelho, candomblecista, foi vítima de intolerância religiosa dentro do Colégio Estadual Padre Manuel da Nóbrega, na cidade de São Gonçalo, Rio de Janeiro. A estudante foi ofendida por outros estudantes dentro da sala de aula, eles disseram coisas como: "gorda macumbeira" e "macumbeiros têm que morrer". A estudante foi revidar as ofensas e acabou sendo expulsa da sala de aula por uma professora (cf. ZUAZO, 2017).

(14) Em 2017, um estudante candomblecista de um colégio particular da cidade de Cuiabá, Mato Grosso, alegou que foi impedido de entrar na unidade escolar porque estava trajando roupas brancas em uma sexta-feira. O Ministério Público Estadual (MP-MT) instaurou inquérito para apurar a possível prática de intolerância religiosa da escola contra este estudante (cf. ANJOS, 2018).

(15) Em 2018, a professora de História Maria Firmino, candomblecista, foi hostilizada por estudantes e outras pessoas da comunidade escolar ("sai, Satanás", "vou pegar essa feiticeira", "ninguém pode mais do que Deus") após dar aula sobre cultura indígena e cultura afro-brasileira. Este fato ocorreu na Escola Tarcila Cruz de Alencar, na cidade de Juazeiro do Norte, no Ceará. A professora não recebeu nenhum apoio da direção escolar e ainda foi afastada de suas atividades (cf. FREITAS, 2018).

(16) Em 2018, uma estudante umbandista da Escola Municipal Ofélio Leitão, da cidade de Teresina, Piauí, alega que foi expulsa da sala de aula por um professor porque estava usando fios de conta. O professor, por sua vez, alegou que expulsou a aluna da sala porque ela estava dormindo (cf. PEREIRA, 2018).

(17) Em 2018, estudantes do 9ำ ano da Escola Municipal Carmine Botta, na cidade de São Carlos, São Paulo, produziram cartazes sobre respeito e tolerância religiosa e sexual. Os cartazes foram fixados no mural em um dos corredores da escola. Quatro vereadores da cidade receberam uma denúncia e entraram na escola para questionar o objetivo da atividade e 
analisar o conteúdo dos cartazes. Um dos vereadores (Leandro Guerreiro) chegou a arrancar alguns cartazes que, segundo ele, faziam apologia LGBT e contra o cristianismo. A diretora da escola (Cilmara Seneme Ruy), por sua vez, disse que a ação do vereador foi uma violência no espaço escolar: "Ali foi vivenciado, na prática, o que aquelas crianças e adolescentes estavam aprendendo a não fazer" (cf. MARIN, 2018).

(18) Em 2018, a professora Odara Dele da Escola Estadual Conselheiro Ruy Barbosa, na cidade de São Paulo, relatou que sofreu injúrias raciais por parte de alguns estudantes que escreveram na porta da sala de aula o nome dela e "preta galinha do caralho". Odara que é candomblecista relatou também que, anteriormente, em outra unidade escolar, um estudante postou uma foto dela em rede social com a frase: "Hoje vamos ter aula de vodu" (cf. ZYLBERKAN, 2018).

Esses dezoito casos citados, ocorridos entre 2004 e 2018, representam apenas uma pequena parcela de todas as denúncias e de todos os casos, mas apresentam uma multiplicidade de formas da ocorrência da intolerância religiosa no âmbito da educação básica e não são somente casos e denúncias com os atos cometidos por professores e diretores contra estudantes como indicado em alguns relatórios (cf. FERREIRA; GRADELLE, 2017; MDH, 2018). A maior parte dos casos citados foi noticiada pela imprensa e ainda não foi mencionada em estudos sobre a intolerância religiosa. A maior parte dos casos ocorreu na cidade do Rio de Janeiro e na região metropolitana; no entanto, a intolerância religiosa na educação básica aparentemente está disseminada por todo o país, foram noticiados casos ocorridos em todas as regiões brasileiras: um caso do CentroOeste (14), três do Nordeste $(3,15,16)$, dois do Norte $(7,10)$, oito do Sudeste $(1,4,5,8,11,13,17,18)$, e dois do $\operatorname{Sul}(2,9)$.

Seguindo as pistas de pesquisas antropológicas que abordam a intolerância religiosa, é possível classificar esses casos de intolerância religiosa ocorridos no âmbito da educação básica. Primeiramente os casos com atos de intolerância religiosa praticados nas escolas contra os estudantes que são adeptos das religiões afro-brasileiras $(4,8,9,11,13,14,16)$. Os casos com atos de intolerância religiosa praticados nas escolas contra os professores e contra as iniciativas de implementação da lei 10.639 (5, 7, 12, 15, 18). Os casos com atos de intolerância religiosa praticados nas escolas contra os símbolos da herança africana e das religiões afro-brasileiras $(1,3,7,10,12)$. Os casos com manifestações de parlamentares contra os símbolos da herança africana e das religiões afro-brasileiras presentes nos materiais didáticos e nas atividades escolares $(2,17)$. E, por fim, os casos de intolerância religiosa nas representações das religiões afro-brasileiras presentes em livros didáticos (6).

Constata-se que quem mais sofre com a intolerância religiosa nas escolas são pessoas adeptas das religiões afro-brasileiras e negras $(4,8,9,11,13,14$, $15,16,18)$; quem mais comete os atos de

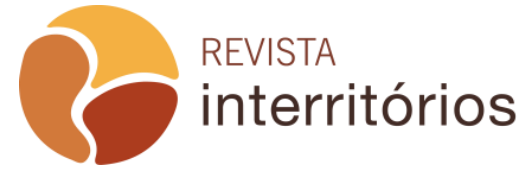

Interritórios | Revista de Educação Universidade Federal de Pernambuco, Caruaru,BRASIL | V.5 N.9 [2019] 
intolerância religiosa nas escolas são pessoas evangélicas (1, 2, 3, 5, 7); e a intolerância religiosa manifesta-se principalmente junto com o racismo e também junto com outros preconceitos como: a homofobia e a gordofobia $(13,17,18)$.

Destaca-se a questão da proibição presente em diversos casos citados $(1,2,3,4,5,8,10,14,15)$. Não são simplesmente proibições genéricas, voltadas contra todas as práticas religiosas e com alguma motivação laicista. Cabe mencionar que na relação entre os agentes do estado e as religiões, é difícil designar algo como estritamente religioso ou estritamente laico, porque diversas práticas podem assumir formas religiosas (cf. ASAD, 1993). Além disso, diversos estudos antropológicos indicam que a presença das proibições pode ser um indício da própria atuação do religioso, mesmo fora do âmbito religioso (cf. DOUGLAS, 1977; GIUMBELLI, 2014). Neste sentido, observa-se que as proibições dos casos citados são voltadas contra as religiões e os símbolos afrobrasileiros e têm motivações religiosas, principalmente a partir de pessoas evangélicas.

Com relação à presença e à atuação do religioso na educação básica, pode-se dizer que o catolicismo ou determinadas religiosidades católicas manifestavam-se na maior parte das escolas brasileiras. No entanto, antes do grande crescimento da população evangélica, estas manifestações cristãs na educação básica não eram voltadas necessariamente contra outras religiões ou outros símbolos religiosos. Os católicos mantinham uma tradição majoritária de aparente aceitação das outras religiões e muitos frequentavam os cultos afrobrasileiros, o que não quer dizer que as religiões afro-brasileiras e outras religiões estavam livres da condição de subalternidade, livres de serem consideradas superstições, livres dos processos de folclorização e livres de qualquer preconceito (cf. VIEIRA; BIAZETTO, 2013). Neste sentido, as manifestações católicas na educação básica, além de manifestações de uma cultura majoritária, do católico como sinônimo de brasileiro, de alguma forma estavam acomodadas e eram consideradas aceitáveis. Já com o crescimento dos evangélicos, as mesmas manifestações cristãs na educação básica ganham novos significados. Por exemplo, a questão da oração do Pai Nosso em sala de aula que, anteriormente, não constituiria um problema ou um ato de intolerância religiosa, nos dias atuais pode ser utilizada para constranger um estudante que é adepto do candomblé.

As manifestações cristãs na educação básica já não estão dentro do contexto do guarda-chuva católico-romano que deseja incluir de forma paternalista todas as outras religiões. A menção a Deus continua sendo amplamente aceitável, mas o Deus evocado muitas vezes não é mais o pai de todas as pessoas; por exemplo, um estudante que é adepto do candomblé pode ser considerado "filho do capeta". Deus tem sido evocado para legitimar posicionamentos contrários às divindades afro-brasileiras (orixás, Exu, Ogum, Pombagira, etc.), porque "ninguém pode mais do que Deus". Os casos citados 
indicam que Deus não tem sido evocado nas escolas para estimular a convivência pacífica entre adeptos de diferentes religiões, mas sim para propagar a guerra espiritual contra tudo que é considerado "macumba", "vodu", "feitiçaria", "do demônio", "de Satanás", "contra o cristianismo", "contra os princípios bíblicos", etc. Dentro deste novo contexto cultural em que Deus é evocado na educação básica para propagar a guerra espiritual, até mesmo os livros didáticos de ensino religioso com conteúdo predominantemente cristão podem ser utilizados como instrumentos da intolerância religiosa dos evangélicos.

Até aqui foi feita a análise de alguns aspectos da intolerância religiosa no Brasil e a análise de alguns casos de intolerância religiosa na educação básica. Agora a análise volta-se para duas atividades propostas na educação básica, especificamente na ministração da disciplina Sociologia no ensino médio.

\section{Considerações sobre duas atividades na educação básica}

Entre os anos de 2011 e 2014, ministrei aulas de Sociologia na rede pública estadual de São Paulo (Secretaria da Educação do Estado de São Paulo, SEE-SP). O conteúdo da disciplina de Sociologia para a primeira série do ensino médio, entre outras coisas, inclui o processo de desnaturalização do olhar dos estudantes e, para isso, uma das estratégias, para desenvolver o espírito crítico dos estudantes e sua capacidade de observação, é propor a pesquisa de campo. Seguem abaixo alguns trechos da orientação da SEE-SP para professores de Sociologia utilizarem a pesquisa de campo em uma atividade proposta aos estudantes:

Diga que é um treino do olhar. (...) Ele consiste na ida dos alunos a um lugar no seu bairro, ou fora dele, que eles não conheçam ou não costumem frequentar. É necessário que eles façam uma pequena descrição do local e das pessoas. (...) Ao escolher o lugar eles podem levar em conta: diferenças de geração (...), diferenças de gênero (...), diferenças de religião (igreja católica, evangélica, centro espírita, terreiro de umbanda ou candomblé, templo budista, mesquita, sinagoga, etc.), diferenças de origem (...), diferença de atividade e costumes (...).

(...) Sugira aos alunos que escolham um lugar em que se sintam confortáveis para ir e que achem interessante conhecer. Não imponha um determinado lugar. (...) Lugares que de alguma forma possam colocá-los em risco devem ser descartados.

(...) digamos que um aluno resolveu descrever uma igreja católica. Como pode saber, só por olhar, que o espaço mais alto no interior da igreja chama-se altar, e que em uma determinada

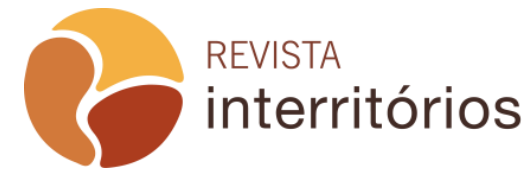

Interritórios | Revista de Educação Universidade Federal de Pernambuco, Caruaru,BRASIL | V.5 N.9 [2019] 
caixa ficam guardadas as hóstias? Como o aluno viu a hóstia, se ela está guardada? Ele só pode descrever o que vê no momento da visita ao local. (SEE-SP, 2013, pp. 12-13)

Esta orientação da SEE-SP recomenda que a observação dos estudantes, em lugares que eles não conheçam ou não costumam frequentar, deve levar em conta também as diferenças de religião. São citados os templos de diferentes vertentes religiosas: "igreja católica, evangélica, centro espírita, terreiro de umbanda ou candomblé, templo budista, mesquita, sinagoga, etc." Destaca-se que a orientação recomenda que os lugares a serem observados não sejam impostos pelos professores e que não sejam escolhidos lugares em que os estudantes se sintam desconfortáveis ou sejam colocados em risco. Apesar de enfatizar que a observação dos estudantes deve levar em conta as diferenças de religião, a orientação apresenta um exemplo de observação em uma igreja católica. Ou seja, não se trata propriamente de um exemplo que incentiva os estudantes a levarem em conta as diferenças religiosas, pois $60,1 \%$ da população paulista declarou-se católica, no censo de 2010; além disso, em diversas cidades do interior de São Paulo os católicos constituem mais de $70 \%$ da população.

É louvável a proposta da atividade com pesquisa de campo e ainda mais louvável a orientação de levar em conta as diferenças de religião. No entanto, diante do novo contexto cultural com o crescimento dos casos de intolerância religiosa na educação básica, não é adequado apresentar apenas o exemplo que privilegia o catolicismo. Se há algum grupo religioso que precisa ser observado sem preconceitos por estudantes e professores, este é o grupo dos adeptos das religiões afro-brasileiras. Pode-se argumentar que diversas cidades paulistas não possuem templos afro-brasileiros para serem observados ou que muitos estudantes se sentirão desconfortáveis em festas ou em templos afrobrasileiros. De qualquer maneira, a orientação da SEE-SP deveria sugerir exemplos de pesquisas de campo que privilegiam a observação de grupos religiosos minoritários, principalmente os afro-brasileiros, e incentivar um maior envolvimento dos professores no sentido de mitigar qualquer desconforto dos estudantes. Talvez seja pelo fato da orientação da SEE-SP buscar uma espécie de abstenção e privilegiar o catolicismo é que grupos evangélicos não se manifestam abertamente contra esta atividade.

Em escolas estaduais na zona leste da cidade de São Paulo (no Jardim Imperador e no Parque São Lucas), em 2011, havia um grande percentual de estudantes evangélicos em todas as salas. Estes estudantes, vez ou outra, em comentários com tom de brincadeira, demonizavam as religiões afro-brasileiras mesmo sem conhecê-las efetivamente. Por isso, foi importante propor uma pesquisa de campo relativa às religiões afro-brasileiras. Para evitar maiores transtornos, na escola do Parque São Lucas foi proposto aos estudantes, da primeira série do ensino médio,

\begin{tabular}{l|l} 
REVISTA & $\begin{array}{l}\text { Interritórios | Revista de Educação } \\
\text { interritórios }\end{array}$ \\
Cniversidade Federal de Pernambuco, \\
Caruaru,BRASIL | V.5 N.9 [2019]
\end{tabular}


entrevistarem adeptos da umbanda ou do candomblé. Sugeriu-se um pequeno roteiro para as entrevistas:

$\checkmark$ - O que significa ser um adepto dessa religião afro-brasileira?

$\checkmark$ - Qual a linha ou nação do seu templo ou terreiro?

$\checkmark$ - Como você se relaciona com as divindades? Quais são estas divindades?

$\checkmark$ - Descreva como é a planta do templo ou outro lugar em que realizam os rituais.

$\checkmark$ - Qual é a principal mensagem que a sua religião quer passar?

E outras questões levantadas pelo grupo.

Diversos estudantes, principalmente estudantes evangélicos, manifestaram seu incômodo em realizar o trabalho, mesmo tratando-se de uma simples entrevista, e disseram que não sabiam quem entrevistar, porque supostamente não conheciam nenhum adepto da umbanda ou do candomblé. Diante disso, sugeriu-se que os estudantes procurassem funcionários de lojas de artigos religiosos das proximidades para entrevistarem. Também foi elaborada uma lista com endereços de lojas e templos de umbanda nas proximidades da escola. Não foi pedido que os estudantes observassem nenhum ritual, nem entrassem dentro dos templos; a entrevista poderia ser realizada na calçada ou em outro local. Houve alguns comentários sobre este trabalho na sala dos professores, mas nenhum professor questionou sobre a sua pertinência. Houve uma conversa com o diretor da escola juntamente com a mãe de uma estudante. Esta mãe apresentou uma carta solicitando a revisão do trabalho, ela alegou que sua filha estava sendo constrangida a entrar em contato e entrevistar uma pessoa adepta da umbanda ou do candomblé, o simples fato dela entrevistar esta pessoa iria contra a sua liberdade de crença, pois ela e a mãe eram evangélicas. Segue abaixo trecho da carta redigida pela mãe da estudante:

Eu, XXXX, mãe da aluna YYYY, venho solicitar a revisão de um trabalho solicitado pelo professor da matéria Sociologia ao $1^{\circ} \mathrm{C}$ que como mãe e tutora legal da menor não concordo com a condição imposta para efetuar o trabalho. Quero deixar claro que não me oponho da realização do trabalho que se trata da religião do candomblé e da umbanda, creio que o estudo sobre tais culturas poderá enriquecer os conhecimentos da menor, porém me oponho que a menor tenha que entrevistar pessoas que tenham tais religião como princípio, pois contradiz com o que a menor acredita, esta submissão irá causar constrangimento. Sendo assim peço gentilmente a possibilidade do trabalho ser efetuado por estudos via livros ou internet. Somos da religião 
evangélica protestante e tal situação vai constrangê-la como podemos perceber no Estatuto da Criança e do Adolescente (São Paulo, 27/10/2011).

Ainda nesta conversa com o diretor e com a mãe da estudante, destacouse a importância do trabalho proposto, não somente no sentido de desenvolver o espírito crítico, mas a importância da estudante conhecer a perspectiva do outro, de uma pessoa que professa uma outra crença. Tratava-se também de uma atividade de sensibilização no sentido de combater o preconceito e a intolerância religiosa e, consequentemente, defender a convivência pacífica com respeito às diferentes crenças e aos seus adeptos. Além disso, declarei que também era evangélico como ela e acreditava que uma simples entrevista não ia contra a fé evangélica. A mãe da estudante continuou irredutível e disse que sua filha deveria realizar um outro tipo de trabalho com pesquisa bibliográfica que substituísse a entrevista. O diretor da escola manteve um tom mais conciliador e nitidamente não queria ter problemas com a mãe da estudante. Diante disso, foi proposto um trabalho alternativo, uma pesquisa sobre as religiões afro-brasileiras, aos estudantes que se sentiram constrangidos em realizar a entrevista com a pessoa adepta da umbanda ou do candomblé.

Neste tópico apontou-se que a atividade de observação que apenas sugere que os estudantes devem levar em conta as diferenças religiosas, mas que efetivamente não propõe a observação das religiões afro-brasileiras, supostamente não causa nenhum tipo de reação dos grupos evangélicos. Já a atividade que propõe o contato dos estudantes com adeptos das religiões afrobrasileiras, nem que seja para a realização de uma simples entrevista, pode ser considerada algo que contradiz a fé evangélica e que constrange os estudantes evangélicos.

\section{Considerações finais}

A falta de levantamentos e pesquisas detalhadas dificultam a compreensão das diversas dimensões da intolerância religiosa na educação básica e dificultam também a proposição de medidas para combatê-la. Alguns relatórios sobre a intolerância religiosa sugerem que os atos de intolerância religiosa no âmbito da educação básica são cometidos somente por professores e diretores contra estudantes (cf. FERREIRA; GRADELLE, 2017; MDH, 2018). $A$ análise dos casos noticiados na imprensa e a análise sobre duas atividades propostas na educação básica indicam que os estudantes adeptos das religiões afro-brasileiras ainda são aqueles que mais sofrem ataques caracterizados como intolerância religiosa, mas há também outros tipos de atos de intolerância religiosa na educação básica. Os atos contra os professores e contra as 
iniciativas de implementação da lei 10.639 , os atos contra os símbolos da herança africana e das religiões afro-brasileiras, as manifestações de parlamentares contra os símbolos da herança africana e das religiões afrobrasileiras presentes nos materiais didáticos e nas atividades escolares, e as manifestações contra as representações das religiões afro-brasileiras presentes em livros didáticos. Qualquer levantamento ou pesquisa sobre a intolerância religiosa na educação básica não pode ignorar as diversas dimensões deste problema com os seus diferentes tipos de casos concretos. Os casos analisados aqui representam apenas uma pequena parcela de todos os casos de intolerância religiosa na educação básica, consequentemente outros tipos de casos devem ser identificados e analisados, para além dos cinco tipos apontados.

Constatou-se novamente que o Brasil não é o país da liberdade religiosa consolidada e da convivência pacífica entre diferentes grupos religiosos, e que o religioso continua se manifestando e atuando nas escolas brasileiras. Não trata-se apenas de falta de informação sobre as religiões afro-brasileiras que alimenta os estereótipos, os preconceitos e os próprios atos de intolerância. $O$ religioso que está presente nas escolas já não está associado somente a um Deus paternalista que é o pai de todas as pessoas e que abraça todas as vertentes religiosas. Nos últimos anos, o religioso que vem ganhando espaço nas escolas está associado a um Deus belicoso que propaga a guerra espiritual contra o mal, principalmente contra as religiões afro-brasileiras. Com isso, não há somente resistência aos conteúdos relacionados à cultura africana e afrobrasileira de um modo geral, mas também proibições que se voltam especificamente contra as religiões e contra os símbolos afro-brasileiros que, por sua vez, são amplamente demonizados pelos evangélicos. São diversos estudantes, professores e demais profissionais da educação, além de pais e de parlamentares, que simplesmente não têm qualquer respeito pelas religiões afrobrasileiras, pelos seus símbolos e pelos seus adeptos.

Há urgentemente a necessidade de se forjarem novos hábitos na educação básica. Entre estes novos hábitos, precisam estar regularmente presentes as atividades de observação e de valorização das religiões afrobrasileiras. Os estudantes, os professores e os demais profissionais da educação, principalmente aqueles que se declaram evangélicos, precisam estar permanentemente em contato e em diálogo com os religiosos afro-brasileiros. A educação básica de um modo geral não pode ser palco de atos e de disputas caracterizados como intolerância religiosa. 


\section{REFERÊNCIAS}

ALVES, A.; FIOROTTI, S. É preciso dizer não à intolerância religiosa no Brasil. In:

Página do Coletivo por uma Espiritualidade Libertária. São Paulo, 2014.

ANJOS, L. MP-MT apura suposto ato de intolerância religiosa após aluno que pertence ao candomblé ser barrado em porta de escola. In: G1 MT. Cuiabá, 2018.

ARAÚJO, P. C. Entre o terreiro e a escola: lei 10.639/2003 e intolerância religiosa sob o olhar antropológico. Tese (doutorado em Ciências Sociais). São Paulo: PUCSP, 2015.

ARAÚJO, P. C.; FIOROTTI, S. "Ser do candomblé é assumir o risco de ser discriminado o tempo todo": entrevista com Patrício Carneiro Araújo. In: Página do Coletivo por uma Espiritualidade Libertária. São Paulo, 2017.

ASAD, T. Genealogies of Religion: Discipline and Reasons of Power in Christianity and Islam. Baltimore and London: The Johns Hopkins University Press. 1993.

BAKKE, R. R. B. Na escola com os orixás: o ensino das religiões afro-brasileiras na aplicação da lei 10.639/2003. Tese (doutorado em Antropologia Social). São Paulo: USP, 2011.

BASILIO, A. L. Quinze anos depois, lei 10.639 ainda esbarra em desconhecimento e resistência. In: Carta Educação. São Paulo, 2018.

BOECHAT, B. Estudante agredida por intolerância religiosa dentro de escola não quer voltar ao colégio. In: Extra. Curitiba, 2015.

BORGES, P. Livros didáticos de religião possuem conteúdo preconceituoso. In: Portal iG Último Segundo, Brasília, 2010.

BORTOLETO, M. "Não viemos para fazer aliança": faces do conflito entre adeptos das religiões pentecostais e afro-brasileiras. Dissertação (mestrado em Antropologia Social). São Paulo: USP, 2014.

DINIZ, D.; LIONÇO, T.; CARRIÃO, V. Laicidade e ensino religioso no Brasil. Brasília: Letras Livres / UnB / Unesco, 2010.

DOUGLAS, M. Pureza e perigo. São Paulo: Perspectiva, 1966.

FERREIRA, P.; GRADELLE, R. Adeptos de religiões afro-brasileiras relatam preconceito em sala de aula. In: Jornal O Globo, Rio de Janeiro, 2017.

FIOROTTI, S. Qual deve ser o lugar da religião na educação básica? In: Educação \& Participação, São Paulo, 2017.

FREITAS, C. Professora é substituída após dar aula sobre religião africana em escola no Ceará. In: G1 CE, Fortaleza, 2018. 
FRESTON, P. Breve história do pentecostalismo brasileiro. In: Antoniazzi, A.; et al., Nem anjos, nem demônios. Petrópolis: Vozes, 1994. pp. 67-159.

GARRIDO, B. S. Livros didáticos de ensino religioso. In: Acta Scientiarum. Maringá, v. 34, n. 2, 2012. pp. 207-215.

GIUMBELLI, E. Um projeto de cristianismo hegemônico. In: SILVA, V. G. (org.), Intolerância religiosa: impactos do neopentecostalismo no campo religioso afrobrasileiro. São Paulo: Edusp, 2007. pp. 149-169.

GIUMBELLI, E. Símbolos religiosos em controvérsias. São Paulo: Terceiro Nome, 2014.

MACEDO, E. Orixás, caboclos e guias: deuses ou demônios? 14. ed. Rio de Janeiro: Unipro, 1997.

MACHADO, M. Aluno é barrado em escola municipal do Rio por usar guias do candomblé. In: G1 Rio, Rio de Janeiro, 2014.

MARIANO, R. Neopentecostais. São Paulo: Loyola, 1999.

MARIN, A. Trabalho escolar sobre intolerância gera polêmica com vereadores em São Carlos, SP. In: G1, São Carlos e Araraquara, 2018.

MARIZ, R. Livros de ensino religioso demonstram preconceito contra homossexuais e ateus. In: Correio Braziliense, Brasília, 2010.

MARTINS, A. Lendas de Exu. 2. ed. Rio de Janeiro: Pallas, 2008.

MDH. Balanço geral (Disque 100) 2011 a 1.sem.2018: discriminação religiosa . Brasília: MDH, 2018.

MELO, T. Evangélicos se recusam a apresentar projeto sobre cultura africana, no AM. In: Portal G1 AM. Manaus, 2012.

MENDONÇA, A. G. O neopentecostalismo. In: Protestantes, pentecostais e ecumênicos. 2. ed. São Bernardo do Campo: Umesp, 1994. pp. 127-140.

MONTEAGUDO, C. Escola onde estudante sofreu discriminação religiosa pede desculpas ao aluno. In: Extra, Rio de Janeiro, 2009a.

MONTEAGUDO, C. Professora acusa diretora de escola em Macaé de perseguição. In: Extra, Rio de Janeiro, 2009b.

OLIVEIRA, M. C. C. Coleção História Paratodos: Ensino Fundamental, $1^{\underline{a}}$ a $4^{\underline{a}}$ séries. São Paulo: Scipione, 2004.

ORO, A. P. Neopentecostais e afro-brasileiros. In: Debates do Ner, Porto Alegre, v. 1, nov. 1997. pp. 10-36.

PEREIRA, R. Aluna denuncia que foi expulsa de sala por usar colares de umbanda; polícia investiga. In: Cidade Verde, Teresina, 2018. 
SEE-SP. Caderno do professor: sociologia, $1^{\text {a }}$ série, ensino médio, v. 1. 1. ed. rev. São Paulo: SEE-SP, 2013.

SILVA, V. G. Neopentecostalismo e religiões afro-brasileiras. In: Mana, Rio de Janeiro, v. 13, n. 1, 2007, pp. 207-236.

SILVA, V. G. Prefácio ou notícias de uma guerra nada particular. In: Silva, V. G. (org.), Intolerância religiosa: impactos do neopentecostalismo no campo religioso afrobrasileiro. São Paulo: Edusp, 2007b. pp. 9-28.

SILVA, V. G. Exu Brasil. Tese (livre-docência em Antropologia Social). São Paulo: USP, 2013.

SÓTER, G.; YURI, A. Alunos são proibidos de apresentar trabalho sobre entidade do candomblé. In: G1 PA, Belém, 2016.

VIEIRA, C.; BIAZETTO, F. C. B. Escola: lugar de discutir religião? In: Figueiredo, J. (org.), Nkisi na diáspora. São Paulo: Acubalin, 2013. pp. 65-74.

WAGER, C. P. Oração de guerra. São Paulo: Unilit, 1992

ZUAZO, P. Jovem é vítima de intolerância religiosa dentro de escola em São

Gonçalo. In: Extra. Rio de Janeiro, 2017.

ZYLBERKAN, M. Professora vítima de racismo revive agressões da infância: "Fui chamada de macaca". In: Folha Cotidiano. São Paulo, 2018. 